\title{
Role of endoscopy in evaluating upper gastrointestinal tract lesions in rural population
}

\author{
Sharanabasavaraj Javali, M. Madan ${ }^{1}$, M. L. Harendrakumar ${ }^{2}$, M. S. Mahesh ${ }^{1}$ \\ Department of General Surgery, Vydehi Institute of Medical Sciences, Bengaluru, ${ }^{1}$ Departments of General Surgery and ${ }^{2} \mathrm{Pathology}$, Sri Devraj \\ Urs Medical College, Kolar, Karnataka, India
}

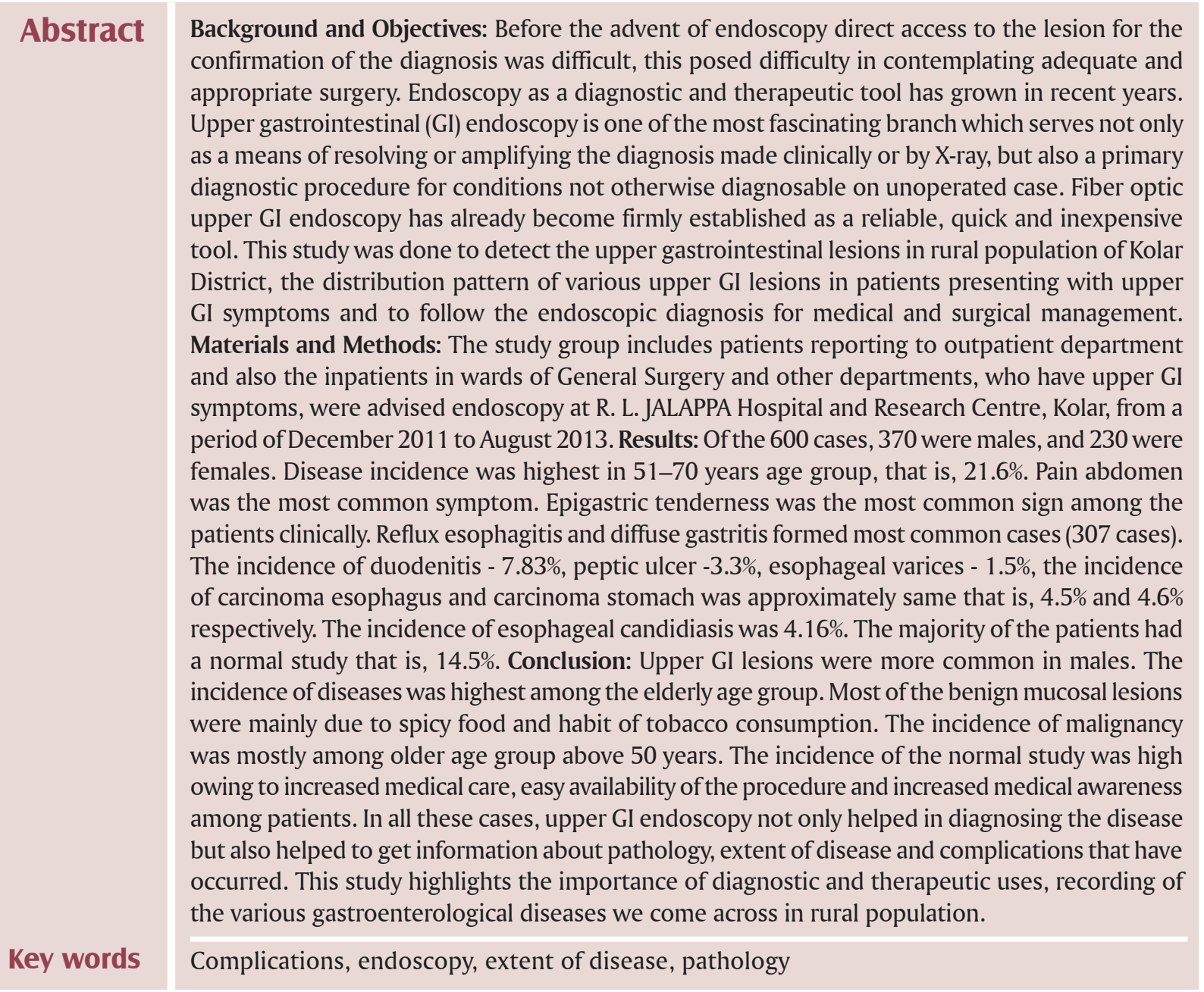

Address for correspondence:

Dr. Sharanabasavaraj Javali, Department of General Surgery,

Vydehi Institute of Medical Sciences and Research Centre,

Bengaluru, Karnataka, India.

E-mail: dr.s.c.javali@gmail.com

\begin{tabular}{|l|c|}
\hline \multicolumn{2}{|c|}{ Access this article online } \\
\hline \multirow{2}{*}{$\begin{array}{l}\text { Website: } \\
\text { www.jdeonline.in }\end{array}$} & Quick Response Code \\
\hline DOI: & \\
10.4103/0976-5042.159238 & \\
\hline
\end{tabular}

This is an open access article distributed under the terms of the Creative Commons Attribution-NonCommercial-ShareAlike 3.0 License, which allows others to remix, tweak, and build upon the work non-commercially, as long as the author is credited and the new creations are licensed under the identical terms.

For reprints contact: reprints@medknow.com

How to cite this article: Javali S, Madan M, Harendrakumar ML, Mahesh MS. Role of endoscopy in evaluating upper gastrointestinal tract lesions in rural population. J Dig Endosc 2015;6:59-65. 


\section{Introduction}

What is endoscopy is it an instrument or technique or it is a "Revolution or Evolution"? Many have come to understand the meaning of endoscopy as merely that of technology or instrumentation. Diagnosis and localization of its afflictions relied for many decades on barium radiology, which provides indirect data in black and white. The situation has changed dramatically since the late 1960s with the introduction of fully flexible and maneuverable endoscopes. Upper gastrointestinal (GI) lesions include patients presenting with symptoms of acid-peptic disease recurrent vomiting, dysphagia, hematemesis, etc., The prevalence of gastro-esophageal reflux diseases is more in western countries compared to Asia. The complications such as duodenal ulcers and strictures, Barrett esophagus and esophageal adenocarcinoma, can be greatly reduced if early diagnosis and screening are done by endoscopy. ${ }^{[1]}$

Peptic ulcer (duodenal and gastric ulcer) is common in men and prevalence is increased with age with a peak prevalence of $28.8 \%$ in $5^{\text {th }}$ decade of life. ${ }^{[2]}$ The role of endoscopy in bleeding peptic ulcer disease is significant. It is an effective tool in diagnosis, prognostication, and therapy of bleeding peptic ulcer.

The studies have shown that endoscopic intervention has led to a reduction in a blood transfusion, shortened Intensive Care Unit and hospital stays. It has decreased the need for surgery and lowered the mortality rate. ${ }^{[3,4]}$

In this rural population of Kolar, we routinely encounter patients with upper GI symptoms. Hence, the need for the study is early detection of upper GI lesions by endoscopy and later evaluating the disease for appropriate management.

\section{Materials and Methods}

This study entitled "Role of endoscopy in evaluating upper GI tract lesions in rural population" was conducted in 600 cases at R. L. Jalappa and Research Center Kolar during the year December 2011 to September 2013.

In all the cases, the endoscope used was the fiberoptic OLYMPUS endoscope connected to DELL LCD monitor $21 " \mathrm{PC}$.

Patients were selected at random for the study and fell into two categories:

- Inpatients-referred and emergency

- Outpatients received through OPD.

In some of the cases, the radiological examination was done prior to endoscopy. In both the categories, the cases which presented with the history and clinical findings suggestive of upper GI tract disorders were accepted for endoscopic examinations.

\section{Symptoms}

- Upper abdominal pain vomiting

- Hematemesis/malaena

- Dysphagia

- Lump in abdomen

- Anorexia/weight loss

- Sensation of fullness after meals

- Weakness and tiredness

- Retrosternal burning with regurgitation.

Signs

- Epigastric tenderness

- Supraclavicular lymphnodes

- Lump in upper abdomen

- Visible upper abdominal peristalsis

- Ascites

- Jaundice.

\section{Investigations}

Following investigations were routinely done before endoscopic examination:

- Hemoglobin

- Stool for occult blood

- LFT in jaundice.

Barium examination (if necessary). The examination was carried out under local anesthetic solution using lignocaine viscus $2 \%$ spray, sprayed 5 min before the procedure.

Since fiberoptic endoscopy is simple and safe, we did not encounter any complications. Inadequate or improper explanation makes patient apprehensive, this is true especially with children and elderly. It is most important to have patient's co-operation to complete the procedure safely. Both safety of the patients and instrument are important for the endoscopist. Positioning of the patient is also equally important for better orientation during visualization of the interior, apart from passing the scope. Mild sedation definitely helps in apprehensive patients, but sometimes it may make the patient more uncooperative under sedation. Good anaesthetization (local) is very essential, as this procedure may irritate pharynx and cause severe bouts of cough in some patients.

Endoscopic methods of biopsy (wherever necessary) used in our series were multiple quadrant biopsy with a biopsy forceps (especially in cases of suspected carcinoma of the stomach, esophagus, etc.

Photographic studies and video recording were done in cases of any positive and diagnostic findings.

Out of these 600 cases, which were randomly selected, few could be followed up during their course of treatment in the hospital and after discharge for a period varying from 2 months to more than a year. 


\section{Results}

Of the 600 patients studied, the maximum number of patients belonged to the age group of 61 years and above $(25.1 \%)$. The minimum number of patients studied belonged to the age group of 11-20 years constituting 18 cases $(3 \%)$.

Of the 600 patients studied, 370 patients were males $(61.6 \%)$ and 230 were females $(28.4 \%)$. Of the 600 cases studied, it has been observed that the maximum number of GI lesions was in the stomach followed by esophagus and duodenum. Benign lesion in esophagus, stomach and duodenum was seen in 108 cases, 241 cases and 81 cases respectively. Malignant lesions of stomach and esophagus were seen in 28 and 27 cases respectively. Only two cases of carcinoma duodenum were seen in our study.

\section{Distribution of malignant lesions of the upper gastrointestinal tract}

Of the 600 cases studied 57 cases were diagnosed on endoscopy as malignant lesions. Of the 57 cases studied 28 cases were carcinoma stomach, of which 20 were seen in males, eight were seen in females.

Of the 57 cases studied 27 cases were carcinoma esophagus, of which 15 were seen in males, 12 were seen in females.

Table 1: Distribution of patients according to age

\begin{tabular}{|l|c|c|}
\hline Age group & Number of Patients & Percentage \% \\
\hline $\mathbf{1 1 - 2 0}$ & 18 & 3 \\
\hline $\mathbf{2 1 - 3 0}$ & 97 & 16.1 \\
\hline $\mathbf{3 1 - 4 0}$ & 98 & 16.33 \\
\hline $\mathbf{4 1 - 5 0}$ & 129 & 21.5 \\
\hline $\mathbf{5 1 - 6 0}$ & 108 & 18.00 \\
\hline $\mathbf{6 1 -}$ above & 151 & 25.1 \\
\hline Total & $\mathbf{6 0 0}$ & $\mathbf{1 0 0 . 0 0}$ \\
\hline
\end{tabular}

Table 2: Distribution of patients according to sex

\begin{tabular}{|l|c|c|}
\hline Sex & Number of patients & Percentage \\
\hline Male & 370 & 61.6 \\
\hline Female & 230 & 28.4 \\
\hline Total & $\mathbf{6 0 0}$ & $\mathbf{1 0 0}$ \\
\hline
\end{tabular}

Table 3: Distribution of patients according to etiology

\begin{tabular}{|c|c|c|}
\hline Aetiology & Number of Patients & Percentage \\
\hline Reflux ocsophagitis & 41 & 6.8 \\
\hline Reflux oesophagitis with gastritis & 30 & 5.9 \\
\hline Oesophageal varices & 09 & 1.5 \\
\hline O. Candidiasis & 25 & 4.16 \\
\hline Stricture cesophagus & 02 & 0.33 \\
\hline Carcinoma ocsophagus. & 27 & 4.5 \\
\hline Acute diffuse gastrititis & 74 & 12.33 \\
\hline Chronic gastritis & 75 & 13.8 \\
\hline Atrophic gastritis & 04 & 0.6 \\
\hline Reflux bile gastritis & 36 & 6 \\
\hline Erosive gastritis & 43 & 7.16 \\
\hline Pyloric stenosis & 04 & 0.6 \\
\hline Chronic gastric uleer & 05 & 0.8 \\
\hline Drodenal ulcer & 15 & 2.5 \\
\hline Carcinoma stombch & 28 & 4.6 \\
\hline Foreign body stomach & 04 & 0.66 \\
\hline Duodenitis & 37 & 6.16 \\
\hline Gastroduodenitis & 20 & 0.6 \\
\hline Duodenal polyp & 06 & $T$ \\
\hline Worm infestation & 10 & 0.6 \\
\hline Carcinoma duodenum & 03 & 0.5 \\
\hline Drodenal diverticula & 03 & 0.5 \\
\hline Oesophagal polyp & 01 & 0.16 \\
\hline Normal study & 88 & 14.5 \\
\hline Resurrenese & 02 & 0.33 \\
\hline Pt not prepared well & 02 & 0.33 \\
\hline Un co-opcrative pt's & 02 & 0.33 \\
\hline Indentation of stomach. & 02 & 0.33 \\
\hline Indentation of oesophagus & 02 & 0.33 \\
\hline Total & 600 & 100 \\
\hline
\end{tabular}

Table 4: distribution of benign and malignant lesions of gastrointestinal tract

\begin{tabular}{|l|l|l|l|l|}
\hline Type of Lesion & Oesophagus & Stomach & Duodenum & Total \\
\hline Benign & 108 & 241 & 81 & 430 \\
\hline Malignant & 27 & 28 & 2 & 57 \\
\hline Total & 135 & 269 & 83 & 487 \\
\hline
\end{tabular}

Table 5: Distribution of malignant lesions of upper gastrointestinal tract

\begin{tabular}{|c|c|c|c|c|}
\hline Type and site & Male & Female & Total & $\%$ \\
\hline Carcinoma of Stomach & 20 & 8 & 28 & 4.6 \\
\hline $\begin{array}{c}\text { Carcinoma of } \\
\text { Oesophagus. }\end{array}$ & 15 & 12 & 27 & 4.5 \\
\hline Carcinoma Duodenum. & 02 & 0 & 02 & 0.33 \\
\hline Total & $\mathbf{3 7}$ & $\mathbf{2 0}$ & $\mathbf{5 7}$ & $\mathbf{9 . 5}$ \\
\hline
\end{tabular}




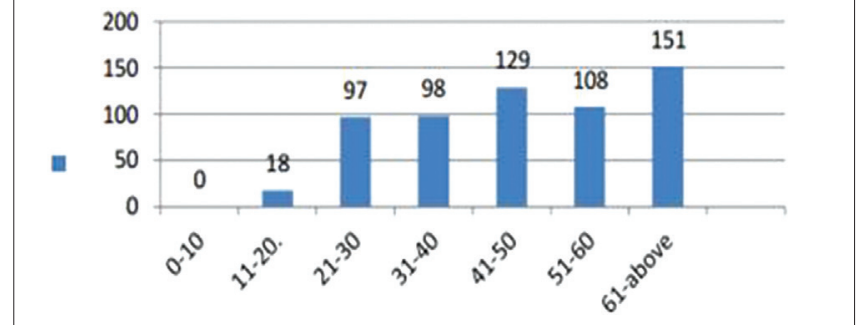

Graph 1: Age distribution

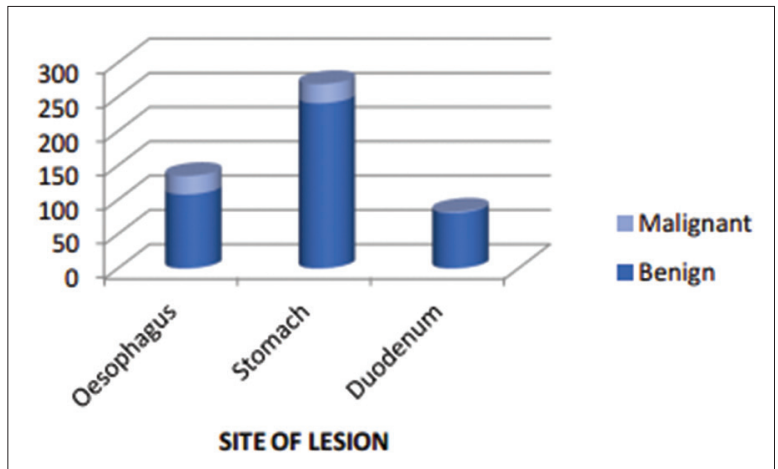

Graph 3: Distribution of benign and malignant lesions in gastrointestinal tract

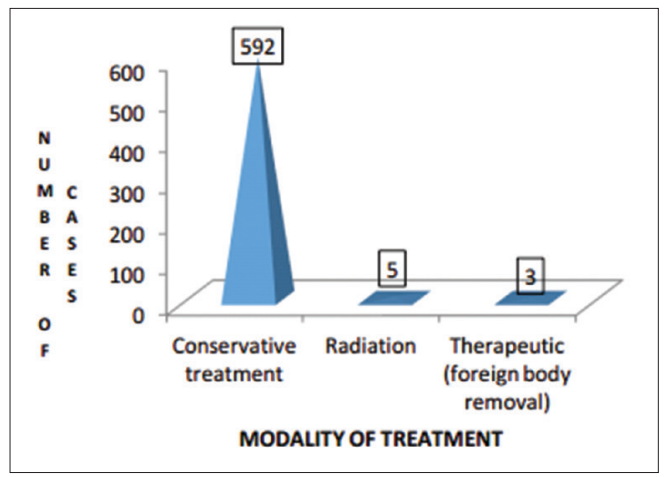

Graph 5: Distribution of patients according to treatment offered

Upper gastrointestinal endoscopy [Figures 1-8]

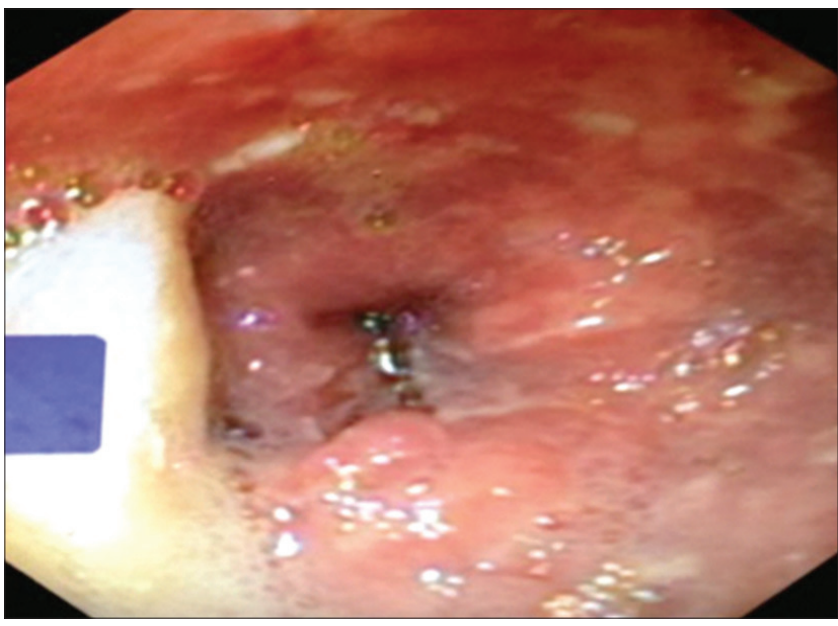

Figure 1: Antral carcinoma

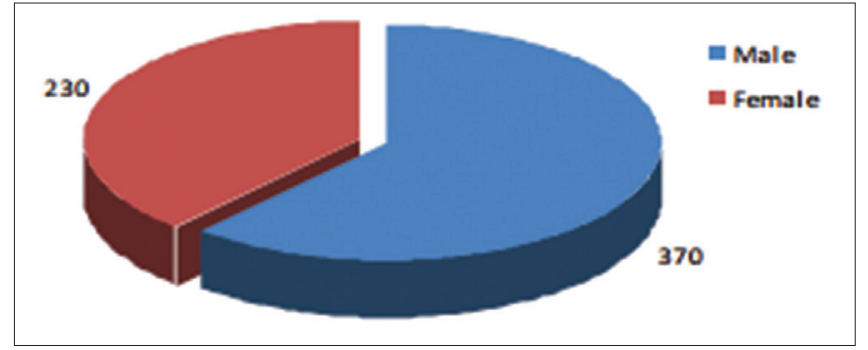

Graph 2: Distribution of patients according to sex

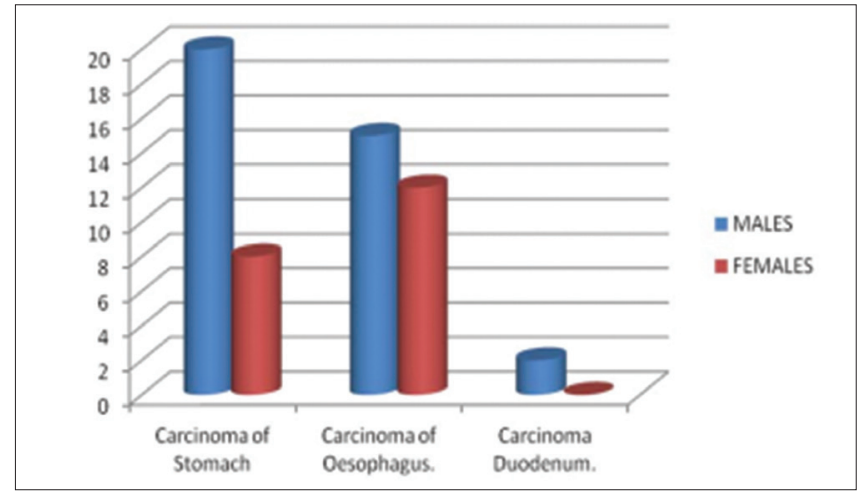

Graph 4: Distribution of malignant lesions of the upper gastrointestinal tract

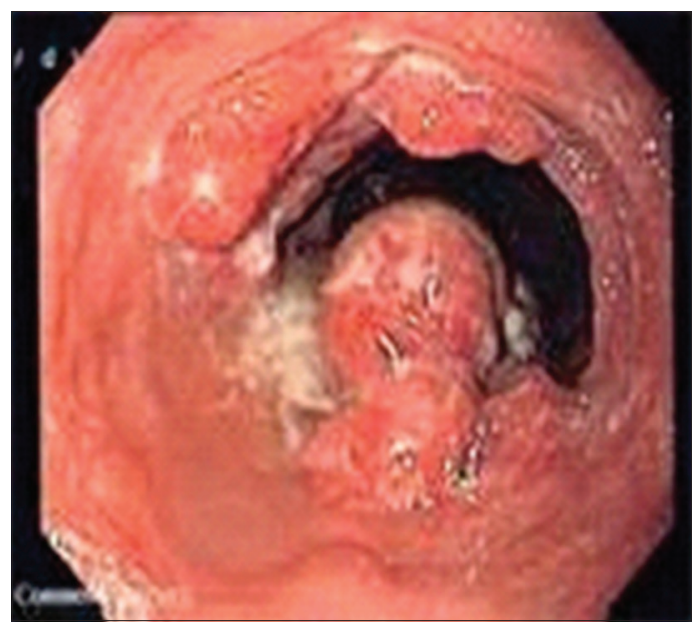

Figure 2: Ca oesophagus Lower $1 / 3^{\text {rd }}$

Of the 57 cases studied two cases were carcinoma duodenum seen in males.

Out of 600 cases studied, $592(98.6 \%)$ patients were managed conservatively, $5(0.83 \%)$ patients received radiation, and $3(00.3 \%)$ had endoscopic treatment of foreign body removal [Tables 1-5 and Graphs 1-5].

\section{Discussion}

This is a prospective study conducted in Department of General Surgery from December 2011 to September 2013 at Journal of Digestive Endascopy - Vol 6 | Issue 2 | April-June 2015 


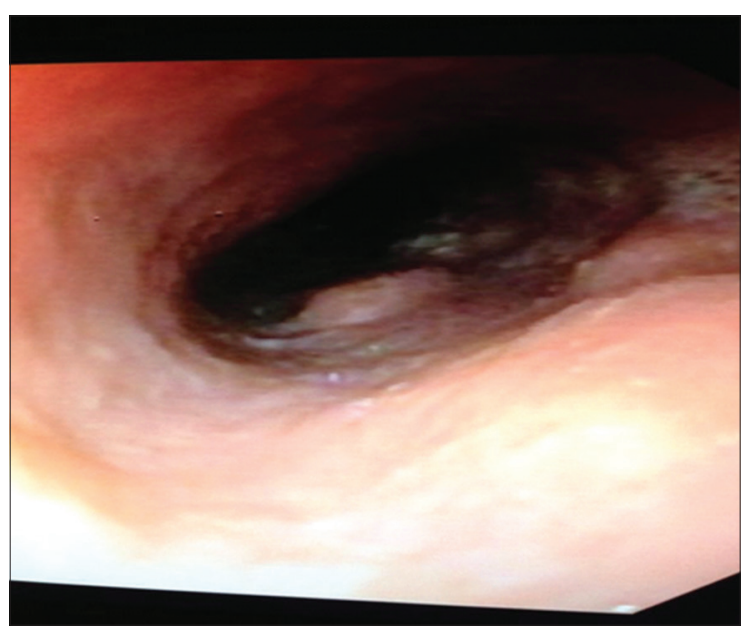

Figure 3: Ca esophagus middle $1 / 3^{\text {rd }}$

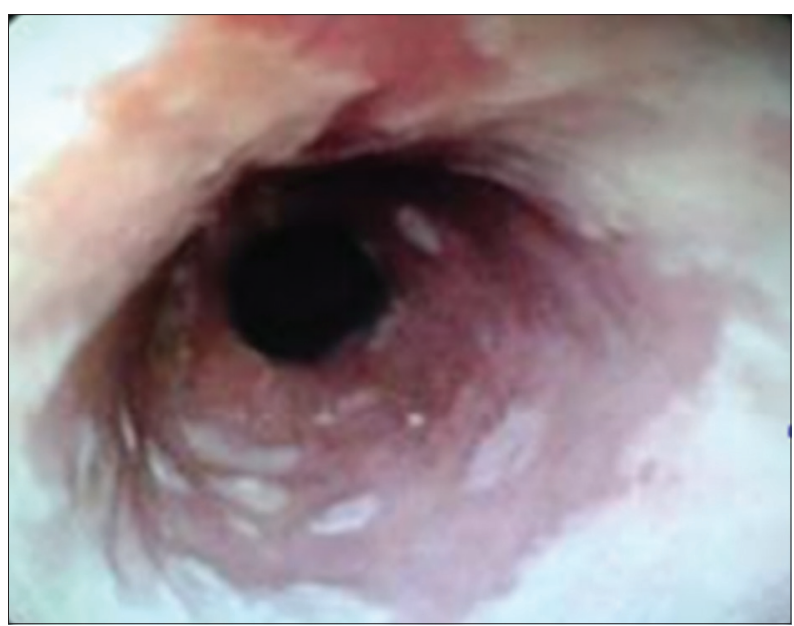

Figure 5: Esophageal candidiasis

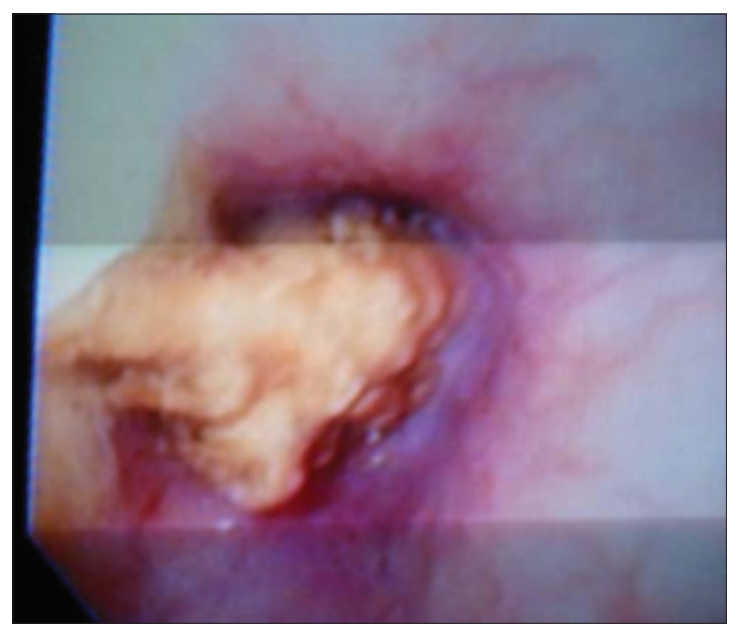

Figure 7: Foriegn body esophagus

Sri Devaraj Urs Academy of Higher Education And Centre, R.L. Jalappa Hospital, Tamaka, Kolar. 600 cases who fulfilled the inclusion criteria were included in the study and were subjected to endoscopy.

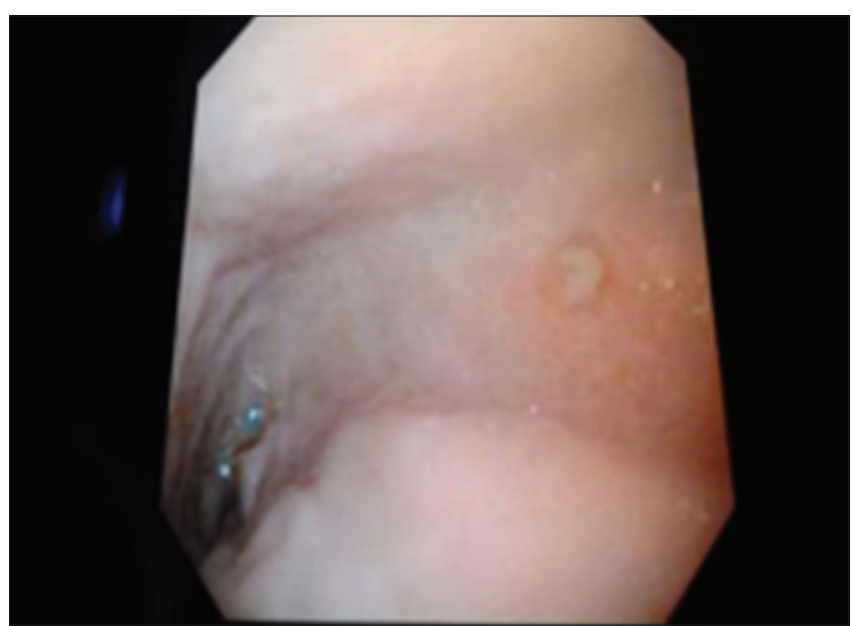

Figure 4: Duodenal ulcer

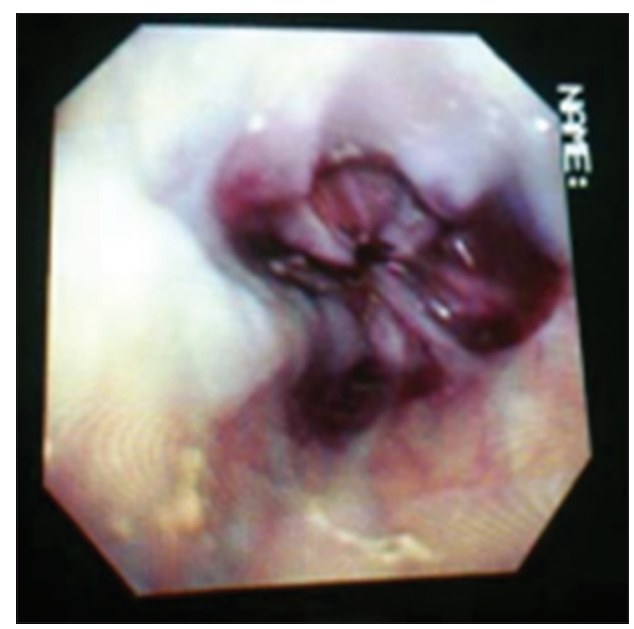

Figure 6: Esophageal varices

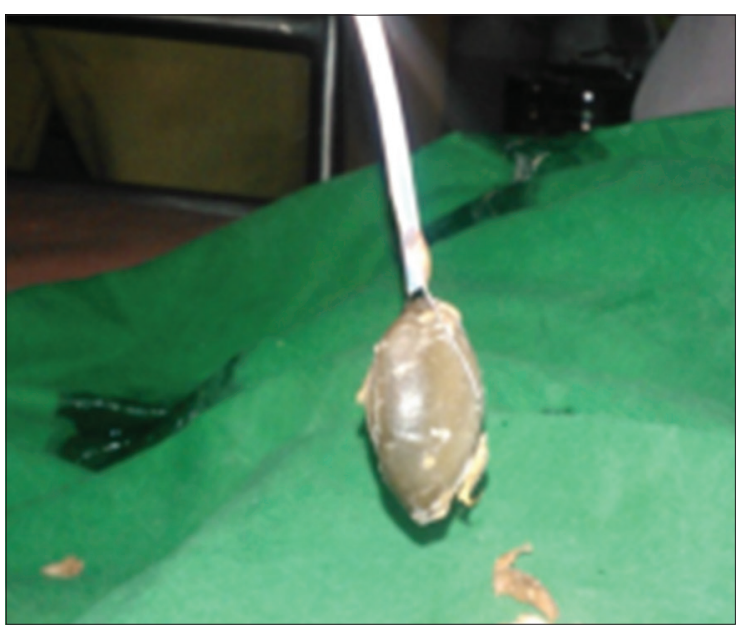

Figure 8: Foreign body removed with snare

In the present study, maximum number of cases subjected to fiber optic endoscopy belonged to the age group of 61 years and above (25.1\%) and 51-60 years (21.5\%). In a similar study by Ray and Pal done at Referral Railway 
Hospital, Kolkata, the mean age group of the study was 51-60 years. ${ }^{[5]}$ In Kuwait series maximum number of patients were in $21-30$ years of age group $(67 / 211)$ adult age group, that is, $21.6 \%$ was affected more than any other age groups. ${ }^{[6]}$

In the present study, the maximum patients subjected to endoscopy were males (61.6\%). In the study by naniwadekar and Kuwait series maximum number of patients subjected to endoscopy were males ( $72.5 \%$ and $62 \%$ respectively). The results were similar to our study. ${ }^{[6,7]}$

In the present study, most of the patients presented with pain abdomen followed by vomiting. In the study by Ray and Pal 9398 cases were studied, and most of the patients presented with the similar complaints of pain abdomen. ${ }^{[5]}$ Similarly in a study of Kuwait series most of the patients presented with pain abdomen.

In this study, most of the patients on upper GI endoscopy were found to have chronic gastritis and acute diffuse gastritis.

The incidence of esophagitis and gastritis was $11.8 \%$ and $39.33 \%$ respectively, our results are comparable to study done by Ray and $\mathrm{Pal}$ and Shennak et al. In esophagitis group most of the patients were in the age group of 21-30 years, the incidence of gastritis was in the age group of 60 years and above. This can be explained because of heavy alcohol and smoking consumption in the laborer group of people in this area. Alcohol and smoking lowers the pyloric pressure, and that leads to reflux of bile leading to the damage of gastric mucosal barrier.

Gastric ulcer incidence was low about $0.8 \%$ compared to other studies by Al-Nakib and Al-Liddawi and Ray and Pal which was $5.9 \%$ and $4.9 \%$. In this rural population incidence of gastric ulcer and duodenal ulcer $(2.5 \%)$ was very low, and seen in elderly age group people. This may be attributed to the widespread use of proton pump inhibitors in the elder age group people as PPI are co-prescribed with NSAID'S and antiplatelet agents used for cardiovascular, cerebrovascular and rheumatological diseases. Also, the PPI are available easily over the counter without cost.

The incidence of gastric carcinoma in our study was found to be $4.6 \%$. The $\mathrm{M}$ : F ratio was $2.5: 1$. The incidence of gastric carcinoma was $6.5 \%$ in a study by Ray and $\mathrm{Pal} .{ }^{[5]}$ The ratio of affection of male: female was 3:1 in a study at Tata Memorial Hospital, Bombay. Database of Kidwai Memorial Institute of Oncology (KMIO) 2004-2005, Bangalore, Karnataka the incidence of gastric cancer was $9 \%$. The maximum patients affected were in the age group of 51-70 years Mean age was 58.5 years comparable to 56 years quoted by Tata Memorial Hospital and with 53 years quoted by Nakib. Antral gastric carcinoma was more predominant compared to carcinoma of the stomach in body and fundus.

The incidence of carcinoma esophagus was $4.5 \%$ in our series. Incidence pattern is comparable to $\mathrm{KMIO}$, Bangalore with the incidence of $6.6 \%$ and Ray and $\mathrm{Pal}$ with the incidence of $4.6 \% .{ }^{[5]}$ Out of the total 27 cases, 15 were Males and 12 were Females. In males, the maximum patients affected were in the age group of 60 years and above.

Esophageal Candidiasis in the present study, Incidence was $4.16 \%$, that is, $25 / 600$. It was seen more common among the male of the age group 50-60 years of the affected individuals only 6 of them were sero-positive for HIV. Candidiasis also affected other individuals (who were not sero-positive for HIV), this may be attributed to the advanced age, diabetes mellitus, alcoholism, inhaled gluco-corticoid use in asthmatics and acid suppressive therapy for patients with chronic gastritis. ${ }^{[8,9]}$ It was interesting that not all patients were symptomatic, and our study supports a prevalence of esophageal candidiasis in $20 \%$ of normal healthy individuals. ${ }^{[8,9]}$ All patients were followed and given a course of treatment with oral flucanazole $200 \mathrm{mg}$ on $1^{\text {st }}$ day, followed by $100 \mathrm{mg}$ once daily for at least 2 weeks. Total number of normal study cases were 88 and incidence was $14.5 \%$. Incidence was more in females compared with males. The normal study were more compared to all previous studies. ${ }^{[6,7,10]}$ The increase in normal studies of endoscopy on recent years is mainly because of increased medical care, easy availability of the procedure and increase awareness of health among the population.

The incidence of upper GI lesions namely gastroduodenitis, duodenal polyp were $3.33 \%$ and $0.5 \%$ respectively. We had two cases of stricture esophagus following corrosive acid consumption. And foreign body stomach constituted to around $0.66 \%$ (3 cases).

\section{Financial support and sponsorship}

Nil.

\section{Conflict of interest}

There are no conflict of interest.

\section{References}

1. Vakil N, van Zanten SV, Kahrilas P, Dent J, Jones R; Global Consensus Group. The Montreal definition and classification of gastroesophageal reflux disease: A global evidence-based consensus. Am J Gastroenterol 2006;101:1900-20.

2. Khuroo MS, Mahajan R, Zargar SA, Javid G, Munshi S. Prevalence of peptic ulcer in India: An endoscopic and epidemiological study in urban Kashmir. Gut 1989;30:930-4.

3. Barkun A, Bardou M, Marshall JK; Nonvariceal Upper GI Bleeding Consensus Conference Group. Consensus recommendations for managing patients with nonvariceal upper gastrointestinal bleeding. Ann Intern Med 2003;139:843-57. 
4. Spiegel BM, Vakil NB, Ofman JJ. Endoscopy for acute nonvariceal upper gastrointestinal tract hemorrhage: Is sooner better? A systematic review. Arch Intern Med 2001;161:1393-404.

5. Ray G, Pal S. Trends in endodiagnosis of upper gastrointestinal diseases at a referral railway hospital. J Dig Endosc 2011;2:213-9.

6. Al-Nakib B, Al-Liddawi H. Upper gastrointestinal endoscopy experience in Kuwait: Analysis of 1019 cases. Gastrointest Endosc 1981;23:605-7.

7. Shroff CP, Nanivadekar SA. Endoscopic brushing cytology and biopsy in the diagnosis of upper gastrointestinal tract lesions. A study of 350 cases. Acta Cytol 1988;32:455-60.
8. Mimidis K, Papadopoulos V, Margaritis V, Thomopoulos K, Gatopoulou A, Nikolopoulou V, et al. Predisposing factors and clinical symptoms in HIV-negative patients with Candida oesophagitis: Are they always present? Int J Clin Pract 2005;59:210-3.

9. Underwood JA, Williams JW, Keate RF. Clinical findings and risk factors for Candida esophagitis in outpatients. Dis Esophagus 2003;16:66-9.

10. Shennak MM, Tarawneh MS, Al-Sheikh TM. Upper gastrointestinal diseases in symptomatic Jordanians: A prospective endoscopic study Ann Saudi Med 1997;17:4. 